\title{
A CROSS-SECTIONAL STUDY TO ASSESS THE PREVALENCE OF OCCUPATIONAL STRESS AMONG VILLAGE HEALTH NURSES OF TAMILNADU
}

\author{
Arunmozhi', Sudharshini Subramaniam², (Late) Maheshwari ${ }^{3}$
}

${ }^{1}$ Associate Professor, Institute of Community Medicine, Madras Medical College.

${ }^{2}$ Assistant Professor, Institute of Community Medicine, Madras Medical College.

\begin{abstract}
BACKGROUND
ABSTRACT

Occupational stress is defined as the harmful physical and emotional responses that occur when the requirements of the job do not match the capabilities, resources or needs of the worker. Studies have shown the prevalence of occupational stress to be high among health care providers compared to other professions. Village Health Nurse, the immediate health care provider at health sub-centre are at increased risk of occupational stress with increasing job demands. While there are studies measuring prevalence of occupational stress among doctors and staff nurses, little is known about these field level health workers.

The aim of this study is to find the prevalence of occupational stress and its associated risk factors among Village Health Nurse s of Tamilnadu.
\end{abstract}

\section{MATERIALS AND METHODS}

The study tool was a self-administered questionnaire prepared in local language (Tamil) which had sections on socio-demographic profile, factors related to stress, and occupational stress measured using Professional Life Stress Scale. The scores categorise stress levels into ranges of Non-problematic (upto 15), Moderate stress (16 - 30), Severe stress (31 - 45) and Very Severe stress (45 - 60). Settings and Design- A cross-sectional study was conducted among 106 Village Health Nurses in a Health Unit District of Tamilnadu. The study tool was a self-administered questionnaire prepared in local language (Tamil) which had sections on sociodemographic profile, factors related to stress, and occupational stress measured using Professional Life Stress Scale. The scores categorise stress levels into ranges of Non-problematic (upto 15), Moderate stress (16 - 30), Severe stress (31 - 45) and Very Severe stress ( $45-60)$. Descriptive and inferential statistics was used appropriately. A ' $p$ ' value of less than 0.05 was considered to be significant.

\section{RESULTS}

Among the study participants, $79.2 \%$ (84 out of 106) had moderate or severe occupational stress and $8.4 \%$ had severe stress. There was no statistically significant difference in the prevalence of occupational stress based on socio-demographic profile. Among work related stress factors, being a single earning member in the family, having less sleep in the night ( 6 hours), traveling for more than an hour to workplace and less salary satisfaction had a higher prevalence of occupational stress. The prevalence of occupational stress was significantly higher among women who had chronic illness for more than 1 year.

\section{CONCLUSION}

The study highlights the high prevalence of occupational stress among the frontline workers of Public Health in Tamilnadu. Occupational stress being identified as one of the occupational hazards, they should be screened periodically for early detection and appropriate management.

\section{KEYWORDS}

Occupational Stress, Village Health Nurses.

HOW TO CITE THIS ARTICLE: Arunmozhi, Subramaniam S, Maheshwari. A cross-sectional study to assess the prevalence of occupational stress among village health nurses of Tamilnadu. J. Evolution Med. Dent. Sci. 2018;7(06):783-787, DOI: $10.14260 /$ jemds/2018/178

\section{BACKGROUND}

India being a member country of United Nations has agreed upon to achieve Universal Health Coverage by 2030 as one of the Sustainable Development Goals. It has been well recognised that health system can function efficiently only with skilled, trained and supported health workforce. Health workforce play a critical role in achieving health related goal.

'Financial or Other Competing Interest': None.

Submission 30-12-2017, Peer Review 24-01-2018,

Acceptance 31-01-2018, Published 05-02-2018.

Corresponding Author:

Dr. Sudharshini Subramaniam,

Assistant Professor,

Department of Community Medicine,

Institute of Community Medicine, Madras Medical College.

E-mail: sudharshinisubramaniam90@gmail.com

DOI: $10.14260 /$ jemds $/ 2018 / 178$

It was also recognised by World Health Assembly that Universal Health Coverage can be achieved only through substantive and strategic investment in the global health workforce. $^{1}$ However, many countries lack the human resources needed to deliver essential health interventions as given by the World Health report in 2006. ${ }^{2}$ To address the health workforce shortage, task shifting was proposed as a strategy in the same report which means delegation of tasks to the lowest category of workers who can perform the tasks successfully. In this context of task shifting, the role of community health workers has gained importance. Systematic reviews have shown that Community Health Workers make a valuable contribution to improve access to and coverage of communities with basic health services. ${ }^{3}$

India since independence has developed an extensive network of primary health centres (PHC) and sub-centres (SC) staffed by doctors and Auxiliary Nurse Midwives (ANMs) 
as well as male health workers to provide basic medical care to huge rural population. In rural health care system, ANM is the key field level functionary who interacts directly with the community and has been the central focus of delivering basic health services. The role of ANM has been changing over time in India. The designation was changed from ANM to "Multipurpose Worker" in 1973 based on Kartar Singh committee recommendations and their role was also extended beyond maternal and child health to include family planning, immunisation, sanitation, infectious disease prevention/ care and antenatal/ delivery care in that order. ${ }^{4}$ In Tamilnadu, a better performing state in terms of health indicators, this cadre is called as Village Health Nurse (VHN). The number of ANM at PHCs and Sub-Centres in Tamilnadu was 8477 in March 2015, which is $4 \%$ of the total ANM in India.

Occupational stress defined as "the harmful physical and emotional responses that occur when the requirements of the job do not match the capabilities, resources or needs of the worker" is of high concern among the health care providers. Studies have shown the prevalence of occupational stress to be high among health care providers compared to other profession.5,6 Though stress by itself is not a disease, it gets transformed affecting physical, mental and psychological wellbeing if it persists for a long duration. Village Health Nurses are at increased risk of occupational stress among the health care providers with increasing job demands. While there are studies measuring prevalence of occupational stress among doctors and staff nurses, little is known about these field level health workers. Hence, this study is done with the objective of finding the prevalence of occupational stress and its associated risk factors among VHNs of Tamilnadu.

\section{MATERIALS AND METHODS}

A cross-sectional study was conducted among the VHNs of Tamilnadu. The sample size was calculated using the formula $\mathrm{Z} \alpha \mathrm{pq} / \mathrm{d}^{2}$. Assuming the occupational stress, prevalence of $50 \%$ with confidence limit of $95 \%$ and $20 \%$ of relative precision, the calculated sample size was 96. Accounting for $10 \%$ non-response rate, the total sample size included was 106. The sampling of the study population was done in 2 stages. In stage 1 , a Health Unit District was randomly selected from 42 Health Unit Districts (HUD). The randomly selected HUD had 267 VHNs working. A sample of 106 VHN was randomly selected from the list using random number generated by the computer. The study participants were explained about the purpose of the study and informed written consent was obtained. Ethical approval for the study was obtained from the Institutional Ethics Committee. The study tool was a self-administered questionnaire prepared in local language (Tamil). Questionnaire had three sections. Section 1 included the socio-demographic profile of the study participants, section 2 included the risk factors related to stress. Section 3 was to measure the occupational stress using the Professional Life Stress Scale (PLSS) developed by David Fontana from the British Psychological Society. ${ }^{7}$ The PLSS had 22 items with a total score of 60 . The level of stress is considered from different aspects: physical symptoms of stress and mental strain, life attitude and the ability to relax, self-attitude, satisfaction with own achievements, relationships with colleagues and supervisors. The scores categorise stress levels into ranges of Non-problematic (upto
15), Moderate stress (16 - 30), Severe stress which requires remedial action (31 - 45) and Very Severe stress (45 - 60). PLSS was translated to Tamil and back translated to English and hence the linguistic validity was ensured.

The collected data was entered in Microsoft Excel and data analysis was done using Statistical Package of Social Sciences (SPSS) version 16. Fisher Exact test and Chi-square test was used. Descriptive and inferential statistics was used appropriately. A p value of less than 0.05 was considered to be significant.

\section{RESULTS}

A total of 106 VHNs participated in the study. The mean age of the women who participated was 49.17 years with standard deviation of 4.892 years. The socio-demographic profile of the study participants is shown in Table 1.

\begin{tabular}{|c|c|c|}
\hline Variable & Category & $\begin{array}{c}\text { Frequency (\%) } \\
\mathrm{N}=106\end{array}$ \\
\hline \multirow{3}{*}{$\begin{array}{l}\text { Age of the Study } \\
\text { Participants }\end{array}$} & $31-40$ years & $4(3.8)$ \\
\hline & $41-50$ years & $54(50.9)$ \\
\hline & 51-60 years & $48(45.3)$ \\
\hline \multirow{4}{*}{$\begin{array}{c}\text { Educational } \\
\text { Status }\end{array}$} & Upto High school & $50(47.2)$ \\
\hline & Higher Secondary & $39(36.8)$ \\
\hline & Degree & $6(5.7)$ \\
\hline & Postgraduate degree & $11(10.3)$ \\
\hline \multirow{4}{*}{\begin{tabular}{|} 
Socio-Economic \\
Class (as per BG \\
Prasad \\
Classification)
\end{tabular}} & Class I & $58(54.7)$ \\
\hline & Class II & $40(37.7)$ \\
\hline & Class III & $6(5.7)$ \\
\hline & Class IV & $2(1.9)$ \\
\hline \multirow{2}{*}{ Marital Status } & Currently Married & $94(88.7)$ \\
\hline & Widow & $12(11.3)$ \\
\hline
\end{tabular}

In this study it is considered to be occupational stress if PLSS score is more than 15 which indicates moderate, severe and very severe stress. Among the study participants, 79.2\% (84 out of 106) had scores more than 15 in PLSS. Among the VHNs with occupational stress, $8.4 \%$ (7 out of 84 ) had severe stress (Table 2).

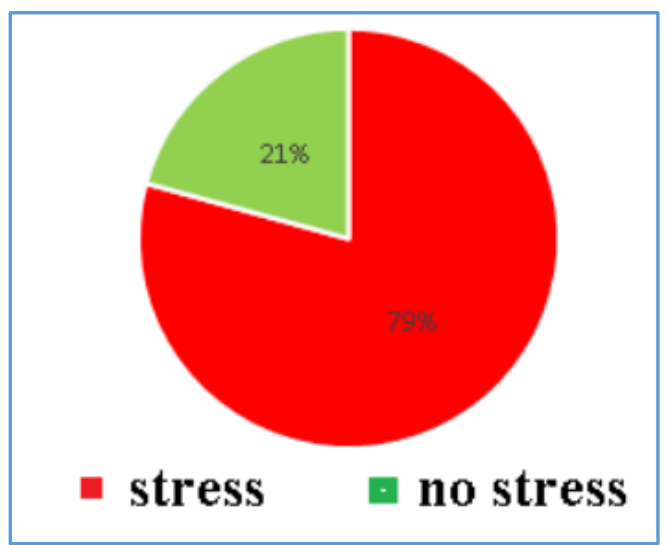

Figure 1. Prevalence of Occupational Stress among VHNs

\begin{tabular}{|c|c|}
\hline $\begin{array}{c}\text { Grade of Occupational } \\
\text { Stress }\end{array}$ & $\begin{array}{c}\text { Frequency (\%) } \\
\mathbf{N = 8 4}\end{array}$ \\
\hline Moderate stress & $77(91.6 \%)$ \\
\hline Severe stress & $7(8.4 \%)$ \\
\hline \multicolumn{2}{|c|}{ Table 2. Grading of Occupational Stress } \\
\hline
\end{tabular}


There was no significant difference in the prevalence of occupational stress based on socio-demographic profile (Table 3). However, occupational stress was more prevalent in the younger age group with higher education level and belonging to higher socio-economic class.

\begin{tabular}{|c|c|c|c|c|c|}
\hline \multirow{2}{*}{\multicolumn{2}{|c|}{ Risk Factor }} & \multicolumn{2}{|c|}{ Occupatonal Stress } & \multirow{2}{*}{ Test Statistic } & \multirow{2}{*}{ P value } \\
\hline & & \multirow{2}{*}{$\begin{array}{c}\text { Present } \mathbf{N}=\mathbf{8 4}(\%) \\
4(100)\end{array}$} & \multirow{2}{*}{$\begin{array}{c}\text { Absent N= 22(\%) } \\
0(0)\end{array}$} & & \\
\hline \multirow{3}{*}{ Age Group } & $31-40$ years & & & \multirow{3}{*}{$\begin{array}{l}\text { Fisher Exact test using Monte } \\
\text { Carlo Simulation }\end{array}$} & \multirow{3}{*}{0.411} \\
\hline & 41-50 years & $40(74.1)$ & $14(24.9)$ & & \\
\hline & 51-60 years & 40 (83.3) & $8(16.7)$ & & \\
\hline \multirow{4}{*}{ Educational Level } & High school & $36(72)$ & $14(28)$ & \multirow{4}{*}{ Fisher Exact Test } & \multirow{4}{*}{0.41} \\
\hline & Higher secondary & $33(84.6)$ & $6(15.4)$ & & \\
\hline & Graduate & $5(83.3)$ & $1(16.7)$ & & \\
\hline & Post graduate & $10(90.9)$ & $1(9.1)$ & & \\
\hline \multirow{2}{*}{ Marital Status } & Married & $75(79.8)$ & $19(20.2)$ & \multirow{2}{*}{ Fisher Exact Test } & \multirow{2}{*}{0.71} \\
\hline & Widow & $9(75)$ & $3(25)$ & & \\
\hline \multirow{4}{*}{$\begin{array}{l}\text { Socio-Economic } \\
\text { Class }\end{array}$} & Class I & $48(82.8)$ & $10(17.2)$ & \multirow{4}{*}{$\begin{array}{c}\text { Fisher Exact Test using Monte } \\
\text { Carlo Simulation }\end{array}$} & \multirow{4}{*}{0.18} \\
\hline & Class II & $29(72.5)$ & $11(27.5)$ & & \\
\hline & Class III & $6(100)$ & $0(0)$ & & \\
\hline & Class IV & $1(50)$ & $1(50)$ & & \\
\hline
\end{tabular}

Among work related stress factors, being a single earning member in the family, having less sleep in the night $(<6$ hours), traveling for more than an hour to workplace and less salary satisfaction had a higher prevalence of occupational stress which was statistically significant (Table 4).

\begin{tabular}{|c|c|c|c|c|c|}
\hline \multirow{2}{*}{\multicolumn{2}{|c|}{ Risk Factor }} & \multicolumn{2}{|c|}{ Occupatonal Stress } & \multirow{4}{*}{$\begin{array}{c}\text { Test Statistic Chi-Square Value } \\
6.856\end{array}$} & \multirow{4}{*}{$\begin{array}{c}\text { P value } \\
0.009 *\end{array}$} \\
\hline & & \multirow{2}{*}{\begin{tabular}{|c|} 
Present $\mathbf{N}=\mathbf{8 4}(\%)$ \\
$71(84.5)$ \\
\end{tabular}} & \multirow{2}{*}{$\frac{\text { Absent } \mathbf{N}=\mathbf{2 2}(\mathbf{\%})}{13(15.5)}$} & & \\
\hline Single Earning & Yes & & & & \\
\hline Member in the Family & No & $13(59.1)$ & $9(40.9)$ & & \\
\hline \multirow{2}{*}{ Sleep Duration } & $<6$ hours & $57(86.4)$ & $9(13.6)$ & \multirow{2}{*}{5.388} & \multirow{2}{*}{$0.020^{*}$} \\
\hline & $\geq 6$ hours & $27(67.5)$ & $13(32.5)$ & & \\
\hline \multirow{2}{*}{$\begin{array}{c}\text { Travel Time to } \\
\text { Workplace }\end{array}$} & $<1$ hour & $34(69.4)$ & $15(30.6)$ & \multirow{2}{*}{5.384} & \multirow{2}{*}{$0.020^{*}$} \\
\hline & $\geq 1$ hour & $50(87.7)$ & $7(12.3)$ & & \\
\hline \multirow{2}{*}{ Salary Satisfaction } & Yes & $32(69.6)$ & $14(30.4)$ & \multirow{2}{*}{4.63} & \multirow{2}{*}{$0.031^{*}$} \\
\hline & No & $52(86.7)$ & $8(13.3)$ & & \\
\hline \multirow{2}{*}{ Duration of Service } & $<10$ years & $29(74.3)$ & $10(25.4)$ & \multirow{2}{*}{0.4873} & \multirow{2}{*}{0.485} \\
\hline & $\geq 10$ years & 55 (82.1) & $12(17.9)$ & & \\
\hline
\end{tabular}

Among the study participants, 68 out of 106 participants had at least one of the chronic illnesses. Presence of chronic illness was significantly associated with occupational stress. The prevalence of occupational stress was significantly higher among women who had chronic illness for more than 1 year (Table 5).

\begin{tabular}{|c|c|c|c|c|}
\hline \multirow{2}{*}{\multicolumn{2}{|c|}{ Chronic Illness }} & \multicolumn{2}{|c|}{ Occupational Stress } & \multirow{2}{*}{ Fisher Exact Test $P$ value } \\
\hline & & \multirow{2}{*}{$\begin{array}{c}\text { Present } \mathbf{N}=\mathbf{8 4}(\mathbf{\%}) \\
23(60.5)\end{array}$} & \multirow{2}{*}{$\frac{\text { Absent } \mathrm{N}=\mathbf{2 2 ( \% )}}{15(39.5)}$} & \\
\hline \multirow{3}{*}{ No. of Chronic Illnesses } & 0 & & & \multirow{3}{*}{$0.002^{*}$} \\
\hline & 1 & $49(89.1)$ & $6(10.9)$ & \\
\hline & 2 & $12(92.3)$ & $1(7.7)$ & \\
\hline \multirow{2}{*}{$\begin{array}{l}\text { Duration of Suffering from } \\
\text { Chronic Illness }(n=68)\end{array}$} & $\leq 1$ year & $6(60)$ & $4(40)$ & \multirow{2}{*}{$0.007^{*}$} \\
\hline & $>1$ year & $55(94.8)$ & $3(5.2)$ & \\
\hline \multirow{2}{*}{$\begin{array}{l}\text { Regular Treatment } \\
\qquad(\mathrm{n}=68)\end{array}$} & Yes & $16(76.2)$ & $5(23.8)$ & \multirow{2}{*}{$0.025^{*}$} \\
\hline & No & 45 (95.7) & $2(4.3)$ & \\
\hline
\end{tabular}

\section{DISCUSSION}

The present study was conducted among Village Health Nurses of a Health Unit District in Tamilnadu. The prevalence of occupational stress among this group of health care providers was $79.2 \%$. That is almost 8 out of $10 \mathrm{VHNs}$ succumbed to some form of occupational stress. Among VHNs who suffered occupational stress, $8.4 \%$ suffered from severe stress, which requires remedial action. The prevalence of occupational stress among health care providers is generally high compared to other professions owing to their unique work environment.5,6 A study conducted among health care professionals in Kolkata using the PLSS found that occupational stress was more common in paramedical workers $(80 \%)$ followed by doctors $(60 \%)$, nurses $(60 \%)$ and technicians (53.3\%). In a study conducted among the health care professionals, working in a hospital at Saudi Arabia showed the prevalence of job stress among this group to be $66.2 \% .^{8}$ In a study conducted among the mental health professionals in Amsterdam, the prevalence of stress was $22 \%$. In this study, stress was measured using Depression 
Anxiety Stress Scale. ${ }^{9}$ A study conducted using perceived stress scale among doctors and nurses in Kanchipuram district of Tamilnadu showed that the prevalence of stress to be $39.5 \% .^{10}$ On comparing with the level of job stress among cadres of health professionals, VHNs seem to have a high prevalence of occupational stress. The job pattern of VHN is even more demanding, as they have to balance providing preventive as well as referral services, work at the sub-centre as well as do field work. These field level health workers are the pillars of the public health system, as they are the ones who implememt any health program in the field. With increasing health programs and increasing population to be covered by each VHN, they are at increased risk of developing stress. Occupational stress among this group should be of serious concern, as it is not only affecting their health but also impairs the quality of care they provide at work. According to the National Institution for Occupational Safety and Health in $2008,60 \%-90 \%$ of low level patient's care may be attributed to stress among health care professionals. ${ }^{11}$

In this study occupational stress was not significantly associated with socio-demographic factors like age, educational status, marital status and socio-economic class of the VHNs. Among the stressors being a single earning member in the family, having less sleep in the night $(<6$ hours), traveling for more than an hour to workplace and less salary satisfaction were found to be statistically significantly associated with occupational stress. Chronic illness was also found to be significantly assoicated with occupational stress. There are many studies which have established the correlation between sleep and occupational stress. A study conducted among staff nurses working in cardiac intensive care unit established a correlation between occupational stress score and sleep quality score. ${ }^{12}$ Similarly, a study conducted among healthy employed men and women living in Stockholm also established that high work demands and physical effort at work are risk indicators for disturbed sleep. It was also established in a study that by eliminating stress $53 \%$ of the sleep reported problems could be prevented. 13

The prevalence of occupational stress was higher among VHNs, who had chronic illness for more than 1 year. Similarly, VHNs who had occupational stress were not on regular treatment compared to those without occupational stress. The potential adverse effects of occupational stress could be psychological (irritability, depression), behavioural (sleep disturbances) and physical (increased blood pressure).14 In this study, it is found that sleeping less than 6 hours and chronic illness to be associated with occupational stress which could actually be the manifestion of adverse effect of stress. The association between occupational stress and chronic illness is a vicious one, as stress is a well known risk factor for chronic illness and having chronic illness itself adds to stress. Stress also has a influence on the compliance of treatment as observed in this study. However, the temporal association could not be established as this being a crosssectional study design. The other limitation of this study is that the questionnaire was self-administered and hence could have been affected by the participants' prevailing emotions. Therefore, there is a possibility of self-administration bias affecting the results.

\section{CONCLUSION}

The study highlights the high prevalence of occupational stress among the frontline workers of Public Health in Tamilnadu. If intervened at the earliest, it may not only be beneficial to the concerned individuals but also for the community they serve. Hence, it may be recommended that stress relieving interventions and strategies may be adopted to relieve the stress. Occupational stress being identified as one of the occupational hazards, these field workers should be screened periodically for early detection and appropriate management.

\section{REFERENCES}

[1] WHO. Global strategy on human resources for health: Workforce 2030. WHO 2010: p. 48 http://www.who.int/hrh/resources/global_strategy_ workforce2030_14_print.pdf?ua=1\%0Ahttp://www.w ho.int/hrh/resources/global_strategy_workforce2030 _14_print.pdf?ua=1\%0Ahttp://who.int/hrh/resources /globstrathrh-2030/en/

[2] Guilbert JJ. The World Health Report 2006: working together for health. Educ Health (Abingdon) 2006;19(3):385-7.

[3] Cleary BJ. Community health workers. 2012;10(11).

[4] Mavalankar DV, Vora KS. The changing role of Auxiliary Nurse Midwife (ANM) in India : implications for Maternal and Child Health (MCH). Working papers, Indian Institute of Management Ahmedabad, Ahmedabad, India. 2008.

[5] Nam SJ, Chun HJ, Moon JS, et al. Job stress and job satisfaction among healthcare workers of endoscopy unit in Korea. Gastrointestinal Endoscopy 2016;49(3):266-72.

http://linkinghub.elsevier.com/retrieve/pii/S001651 0714015132

[6] Shanafelt TD, Boone S, Tan L, et al. Burnout and satisfaction with work-life balance among US physicians relative to the general US population. Archives of Internal Medicine 2012;172(18):1377-85. http://archinte.jamanetwork.com/article.aspx?doi=10 .1001/archinternmed.2012.3199

[7] Fontana D. Managing stress. Leicester \& England: The British Psychological Society in association with Routledge Ltd., 1989.

[8] Salam A, Abu-Helalah M, Jorissen SL, et al. Job Stress and Job satisfaction among health care professionals. European Scientific Journal 2014;10(32):156-73.

[9] Blekemolen JRM, Hulshof CTJ, Sluiter JK. The prevalence of work-related stress complaints among healthcare workers for the disabled participating in a workers' health surveillance program. Occupational Medicine \& Health Affairs 2016;4(6):256. http://www.esciencecentral.org/journals/theprevalence-of-workrelated-stress-complaints-amonghealthcare-workers-for-the-disabled-participating-ina-workers-health-survei-2329-68791000256.php?aid=83922

[10] Sathiya N, Ruwaidha R, Nusrath FS, et al. Perceived stress levels and its sources among doctors and nurses working in a tertiary care teaching hospital, Kancheepuram, Tamil Nadu. National Journal of Community Medicine 2016;7(7)603-8. 
[11] Etim JJ, Bassey PE, Ndep AO. Work - related stress among healthcare workers in Ugep, Yakurr local government area, cross river state, Nigeria: a study of sources, effects, and coping strategies. International Journal of Public Heath, Pharmacy and Pharmacology 2015;1(1):23-34. http://www.eajournals.org/wpcontent/uploads/Work-----Related-Stress-

amongHealthcare-Workers-in-Ugep-Yakurr-Local-

Government-Area.pdf.

[12] Duan X, Wu Q, Zhu X, et al. Improving sleep quality relieves occupational stress in nurses of cardiac surgical intensive care unit. Biomedical Research 2017;28(9):3934-40.
[13] Linton SJ. Does work stress predict insomnia? A prospective study. British Journal of Health Psychology 2004;9(2):127-36. http://doi.wiley.com/10.1348/13591070477389100 5

[14] Rose VE, Richard ML. Occupational health hazards in hospitals. Professional Safety 1980;24(12):11-4. 